Federal Reserve Bank of Minneapolis

Research Department

\title{
ACCOUNTING FOR FORWARD RATES IN MARKETS FOR FOREIGN CURRENCY
}

\author{
David K. Backus, Allan W. Gregory, \\ and Chris I. Telmer* \\ Working Paper 439
}

First Draft: September 1989

Revised: July 1990

NOT FOR DISTRIBUTION

WITHOUT AUTHOR APPROVAL

\begin{abstract}
We examine the behavior of forward and spot exchange rates from the perspective of the representative agent theory of asset pricing. We verify that with moderate risk aversion and time-additive preferences the theory accounts for very little (by our calculations, less than 5 percent) of the variability of expected returns from currency speculation observed for major currencies versus the U.S. dollar. With strong habit persistence, however, the theory can account for one-half to two-thirds of the estimated standard deviation of expected returns from currency speculation. Hansen-Jagannathan bounds imply that the variability of expected returns on currencies, like the equity premium, requires a great deal of variability in intertemporal marginal rates of substitution, some of which is delivered by habit persistence.
\end{abstract}

Keywords: forward and spot rates; risk premiums; contingent claims pricing; habit persistence; marginal rate of substitution.

JEL Classification Numbers: $431,521$.

- Backus, Federal Reserve Bank of Minneapolis and Stern School of Business, New York University; Gregory and Telmer, Queen's University. We thank Philip Dybvig, Campbell Harvey, Dennis Logue, Thomas McCurdy, Gregor Smith, Stanley Zin, and especially Ravi Jagannathan for helpful comments and suggestions, and the National Science Foundation and the Social Sciences and Humanities Research Council of Canada for financial support.

The views expressed are those of the authors and not necessarily those of the Federal Reserve Bank of Minneapolis or the Federal Reserve System. This paper is preliminary and is circulated to stimulate discussion. It is not to be quoted without the permission of the authors. 



\section{Introduction}

Since the advent of flexible exchange rates in 1973 , a large body of statistical work has established that forward rates on major currencies against the American dollar are not optimal predictors of future spot rates. Evidence against the hypothesis that forward rates are optimal predictors of future spot rates, which we refer to as the unbiasedness hypothesis, is reported in studies by Baillie, Lippens and McMahon (1983), Bilson (1981, 1989), Boothe and Longworth (1984), Cumby (1988), Cumby and Obstfeld (1984), Fama (1984), Gregory and McCurdy (1984), Hansen and Hodrick (1980, 1983), Hodrick and Srivastava (1984, 1986), Korajczyk and Viallet (1990), and Mark (1985); a more complete list of references is provided by Hodrick (1987). The evidence implies that expected excess returns from speculation in forward and spot currency markets are predictable, and that they vary considerably over time.

One branch of subsequent research retains the assumption that market forecasts are informationally efficient, and considers the possibility that forward rates contain, in addition to market forecasts of future spot rates, time varying risk premiums. By and large this work has yet to provide a convincing explanation for variation in the expected return. As with other assets, the variability of expected excess returns on forward contracts for foreign currencies are larger than those predicted by intertemporal theories of asset pricing based on a representative aggregate agent with additively-separable preferences. This is implicit in econometric tests by Cumby (1988) and Hansen and Hodrick (1983), in simulations by Macklem (1988), and in numerical examples by Bansal (1990) and Engel (1990).

One problem with representative-agent theories of asset pricing based on 
additively-separable preferences with modest degrees of risk aversion is that they have not been able to reconcile the small amount of variability observed in aggregate consumption data with the relatively large average excess returns observed for many risky assets. The "equity premium puzzle" of Mehra and Prescott (1985) is probably the best known example, but papers by Breen, Glosten, and Jagannathan (1989), Gallant, Hansen, and Tauchen (1989), Grossman, Melino, and Shiller (1987), Hansen and Jagannathan (1989), and Shiller (1984) illustrate similar phenomena for returns on a wide range of assets. Generally speaking, the variability of intertemporal prices in these economies, measured by intertemporal marginal rates of substitution, is much too small to account for the return properties of the data. Macklem's (1988) work demonstrates that this difficulty extends to currencies, where the issue is the variability of the risk premium rather than its mean.

One of the more successful modifications of this framework with respect to the equity premium puzzle is Constantinides' (1990) application of habit persistence. He finds that this kind of intertemporal nonseparability greatly increases the theory's ability to generate average excess returns on equity similar to those seen in time series data. Although the model has some counterfactual features, this line of research appears to us a promising one. In this paper we examine the potential of such a theory to account for expected excess returns from speculation in foreign exchange markets. Unlike equity, average excess returns in the forward market are close to zero. The question, instead, is why expected excess returns are so variable.

Our method of assessing the theory is to build what has come to be called an artificial economy -- a numerical representation of the theory whose properties can be compared to those observed in the data. The theory is complicated enough that analytical results are generally not available. 
We assume that the state variables in the economy take on a finite number of values and characterize the probabilistic environment with a Markov chain. Given values for preference parameters and an equilibrium process for consumption, the aggregate price level, and spot exchange rates, numerical solutions for equilibrium forward prices can be computed. The question we address for ourselves is whether such an economy can account for the estimated variability of expected returns from currency speculation. The theoretical economy has the potential to account for all or part of this variabillty, since the forward price differs from the expected future spot price by a risk premium that can vary with time. The question is whether it varies as much as we see in the data.

We begin by reviewing, in Section 2, properties of monthly forward and spot exchange rates for five major currencies against the U.S. dollar over most of the flexible exchange rate period. We verify that expected excess returns on forward contracts are close to zero, on average, but vary in a predictable manner. Estimates of their variability are computed for use as benchmarks in the theoretical economy. In Section 3 we describe a theoretical economy in which a representative agent's preferences exhibit habit persistence. In Section 4 we outline our methodology for generating asset prices in the theoretical economy and comparing them to the data. We also describe the equilibrium process for consumption growth, inflation, and depreciation and explain how it is estimated from monthly U.S. data for the post-Bretton-Woods era.

In Section 5 we turn to the quantitative properties of the theoretical economy. We show that with additively-separable preferences, and a fortiori under risk neutrality, the standard deviation of expected returns in this 
economy is one to two orders of magnitude smaller than sample estimates. With habit persistence the difference between theory and data is much smaller, and with some parameter values the theory can account for most of the variability seen in the data. Other features of the theoretical economy, including the sampling properties of statistics used to test the unbiasedness hypothesis, are examined in Section 6. We show that with some parameter values the economy generates frequent rejections of the unbiasedness hypothesis and may even reproduce the puzzling inverse relation between excess returns and the forward premium observed in the data.

Sections 7 and 8 are devoted to relating properties of forward prices to those of other assets, and to a broader discussion of the role of habit persistence in theories of asset pricing. We argue that the difficulty theory based on additively-separable preferences has in accounting for the variability of expected excess returns from currency speculation is in one important respect similar to the problems the theory has with other assets. Adapting earlier work by Hansen and Jagannathan (1990) and Shiller (1982), we show that the discrepancy between theory and data can be summarized as insufficient variability in the theory of the intertemporal marginal rate of substitution. In this sense the "puzzle" in foreign currency markets stems from the same source as the equity premium. We also discuss some of the arguments for and against habit persistence as a theoretical basis for asset pricing.

\footnotetext{
We conclude with a few general remarks.
} 


\section{Review of the evidence}

Over the last decade a large number of studies have documented several empirical regularities in the behavior of forward and spot exchange rates. We report some of these in a format similar to Fama (1984); an exhaustive review of the empirical literature is provided by Hodrick (1987, chapters 3,4). In Table 1 we report sample moments for several combinations of forward and spot rates for the U.S. dollar versus the Canadian dollar, the French franc, the deutschemark, the Japanese yen, and the British pound sterling. Data are monthly from 1974 to 1986. We let $s_{t}$ be the spot price in U.S. dollars of one unit of foreign currency and $f_{t}$ the dollar price of a one-month forward contract specifying delivery of one unit of foreign currency, with both payment and delivery taking place one month hence, at date $t+1$.

Most of the literature starts with the hypothesis that forward rates are unbiased and informationally efficient predictors of future spot rates:

$$
f_{t}=E_{t} s_{t+1}
$$

where $E_{t}$ denotes the mathematical expectation conditional on the date-t information set, which we assume includes the present and past values of forward and spot prices. We refer to (2.1) as the unbiasedness hypothesis for forward rates. Under this hypothesis the first variable in Table 1, namely $\left(f_{t}-s_{t+1}\right) / s_{t}$, has conditional and unconditional mean zero. More generally, we might decompose this variable into

$$
\left(f_{t}-s_{t+1}\right) / s_{t}=q_{t}-v_{t+1}
$$

where $q_{t}$ is the predictable component, $v_{t+1}$ is a white noise forecast error associated with the rate of depreciation, $\left(s_{t+1}-s_{t}\right) / s_{t}$, and $E_{t} v_{t+1}=0$. In 
our theoretical economy $\mathrm{q}_{\mathrm{t}}$ will be interpreted as a risk premium, but for now we will simply refer to it as the expected (excess) return from currency speculation. The statistics reported in part (a) of the table suggest that the unconditional mean of the expected return is not very different from zero, either economically or statistically: the largest observed value amounts to an excess return of about 2.3 percent per year.

Part (b) of the table reports statistics for rates of change of spot rates, $\left(s_{t+1}-s_{t}\right) / s_{t}$, and we see that these, too, have been small on average. We may decompose the rate of depreciation into

$$
\left(s_{t+1}-s_{t}\right) / s_{t}=d_{t}+v_{t+1}
$$

where $d_{t} \equiv E_{t}\left(s_{t+1}-s_{t}\right) / s_{t}$ is the rationally expected rate of depreciation and $v_{t+1}$ is defined above. The implication is that mean expected rates of depreciation have been close to zero. The standard deviation of this variable is slightly smaller than that of excess returns, implying that spot rates are slightly better predictors than forward rates of future spot rates.

The final variable in Table 1 is the forward premium, $\left(f_{t}-s_{t}\right) / s_{t}$, a linear combination of the first two variables. Equations (2.2) and (2.3) imply

$$
\left(f_{t}-s_{t}\right) / s_{t}=d_{t}+q_{t} \text {. }
$$

Strong serial correlation in this variable is suggestive of serial correlation in $d$ and/or $q$. The lack of strong serial correlation in the first two variables of the table suggests that serial correlation in $d$ and $q$ is masked by large forecast errors. This interpretation is reinforced by the estimated standard deviations, which are an order of magnitude smaller for the forward premium than for the other variables. 
The evidence of small average excess returns is consistent with the unbiasedness hypothesis. The most common form of evidence against the hypothesis comes from the regression

$$
\left(f_{t}-s_{t+1}\right) / s_{t}=a_{1}+b_{1}\left(f_{t}-s_{t}\right) / s_{t}+u_{t+1} .
$$

The hypothesis implies $a_{1}=b_{1}=0$ and that $u$ is serially uncorrelated. We see in Table 2 that the evidence against $b_{1}=0$ is fairly strong. All five estimates of $b_{1}$ are positive, and four are statistically significant. Expected excess returns are, therefore, predictable using the forward premium. Perhaps the most striking form of this relation is the complementary (and equivalent) least squares regression

$$
\left(s_{t+1}-s_{t}\right) / s_{t}=a_{2}+b_{2}\left(f_{t}-s_{t}\right) / s_{t}-u_{t+1},
$$

with coefficients $a_{2}=-a_{1}$ and $b_{2}=1-b_{1}$. The essence of the unbiasedness hypothesis is that when the forward rate exceeds the spot rate, we expect the future spot to rise by the same amount. As it turns out, four of the five implied estimates of $b_{2}$ in Table 2 are negative, so the hypothesis not only misses the magnitude of the effect, it gets the sign wrong.

More important for our purposes is the implication of the regressions in Table 2 that the difference between the forward rate and the future spot rate contains a predictable component. If it were constant, then we might see a nonzero estimate $a_{1}$, but the nonzero estimates of $b_{1}$ imply variability of the expected excess return from currency speculation. An estimate of the variability of this component is the standard deviation of the fitted values from the regression, which provides, subject to sampling variability, a lower bound on the standard deviation of the predictable component of $\left(f_{t}-s_{t+1}\right) / s_{t}$. These bounds are reported in Table 3 , where we also report similar statistics from regressions of $\left(f_{t}-s_{t+1}\right) / s_{t}$ on the forward premium and its square. We 
see, depending on the functional form of the selected information set, that the standard deviation differs across currencies, from 0.374 percent per month for the Canadian dollar to 1.021 percent for the Japanese yen. The latter corresponds to an annual rate of return of about 12 percent, so the variability in the expected return is large in an economic sense. Since the standard deviations exceed the estimated mean expected returns in Table 1 by a large margin, we infer that expected returns assume both positive and negative values. For the franc and the deutschemark there is a substantial difference between the linear and quadratic regressions, suggesting that there is a disproportionate effect of large forward premiums. The second half of the table reports similar calculations for the expected rate of depreciation, based on fitted values from the complementary regression (2.6). As in Table 1, the estimated standard deviations of the expected rate of depreciation $d$ are smaller than for the expected excess return $q$.

A more practical measure of the predictability of returns from regression (2.5) is the profitability of investment rules based on it. Consider the return from speculating in currency markets using a balanced, or zero net investment, portfolio strategy. One strategy is to buy in the spot market and sell in the forward market when the fitted value of regression (2.5) is positive, and the reverse when it is negative. Let $I_{t}$ be an indicator variable taking the sign of the fitted value from the regression, with $I_{t}=+1$ when $a_{1}+b_{1}\left(f_{t}-s_{t}\right) / s_{t}$ is positive, and $I_{t}=-1$ when it is negative. The return from this strategy is proportional to $x_{t+1}=$ $I_{t}\left(f_{t}-s_{t+1}\right) / s_{t}$, where the factor of proportionality is determined by the amount invested. The means and standard deviations of returns from applying this strategy to each of the five currencies are reported in Table 4, together with their Sharpe ratios (ratios of mean returns to standard 
deviations). The Sharpe ratio is invariant to the amount invested, and serves as a simple measure of the predictability of the return. The tradeoff for currency speculation is quite favorable, in the sense of providing a higher mean return per unit risk than many other assets. The Sharpe ratio implicit in Breen, Glosten, and Jagannathan (1989, Table I, column 6) for a strategy of financing equity purchases with short-term paper is 0.14 (= $0.0080 / 0.0577)$. With the exception of the deutschemark, the ratios for currency speculation are considerably higher. Bilson (1981, 1989) has made a similar point and verified that favorable risk-return tradeoffs hold up in out-of-sample experiments.

All of these features of forward and spot rates have been documented in other studies and can be safely interpreted as empirical regularities for the dollar over the last two decades, and to a limited extent for other currencies over the same period. Using the same dataset to compute bilateral rates between foreign currencies, we find, for example, that the estimated value of $b_{1}$ is 2.938 for the pound-yen rate. Like most of the estimates in Table 2, this value is greater than one and thus implies an inverse relation between the expected rate of depreciation and the forward premium. This feature does not extend, however, to all bilateral rates. The same regression for the franc-deutschemark rate yields an estimated $b_{1}$ of 0.942 , which is statistically indistinguishable from the unbiasedness hypothesis. Evidently the exchange rate process generated by the European Monetary System, and the informal management that preceded it, make the forward rate a better predictor of future deutschemark-franc rates than it is for U.S. dollar spot exchange rates. 


\section{A theoretical economy}

Our theory is a monetary extension of the representative agent theory of asset pricing developed by, among others, Cox, Ingersoll, and Ross (1985), Lucas (1978), and Merton (1972). We examine, specifically, the restriction implied by this theory on the joint stochastic process for consumption growth, inflation, and spot and forward exchange rates. This restriction is a first-order condition for the representative agent; from it we compute equilibrium forward rates given the equilibrium process for consumption, the price level, and the spot rate. Although it is not necessary for our purpose, we might imagine building these relations into a dynamic general equilibrium model with multiple currencies. One such structure is a pure exchange economy with complete markets for state contingent claims. Consumers, one for each country, have homothetic preferences and money is introduced with cash-in-advance constraints, transaction technologies, or preferences for real balances. Examples of such economies are described by Bansal (1990), Lucas (1982), Macklem (1988), and Stulz (1987).

We specify the equilibrium environment as a joint stochastic process for growth rates of consumption $c$, the domestic price level $p$, and the spot rate s. The probabilistic structure is characterized by a stationary, finite state Markov chain with states indexed by $i$. State $i$ at date $t$ determines the triple: $c_{t} / c_{t-1}=x_{i}, p_{t} / p_{t-1}=y_{i}$, and $s_{t} / s_{t-1}=z_{i}$. The evolution of the state is characterized by transition probabilities $\pi_{i j}$ of moving from state $i$ in one period to state $j$ in the next. We combine these probabilities in the transition matrix $\Pi \equiv\left[\pi_{i j}\right]$.

The representative consumer's preferences over stochastic consumption paths for a single aggregate good are characterized by the expected utility 
function

$$
\begin{gathered}
U_{t}=E_{t} \sum_{k=0}^{\infty} \beta^{k} u\left(c_{t+k}^{*}\right), \quad u(c)=\left[c^{1-\alpha}-1\right] /(1-\alpha), \\
c_{t}^{*}=c_{t}-\gamma c_{t-1} .
\end{gathered}
$$

The expectation $E_{t}$ will be understood as conditional on complete knowledge of the state (the integer $i$ ) at date $t$. We assume that the stochastic process for consumption and the value of $\gamma$ guarantee that $c^{*}$ is always positive. The coefficient $\gamma$ captures what Constantinides (1990) terms habit persistence. If $\gamma=0$ we have the additively-separable power utility function used in most earlier studies of dynamic asset pricing. Longer habits are easily introduced, but we have found they add little to the analysis.

We compute asset prices as sums of prices of their component contingent claims. In equilibrium, relative prices of these claims equal ratios of marginal utilities. Thus a real asset yielding a stochastic flow $w_{t+1}$ of the aggregate good at date $t+1$ has a value, in units of the date $t$ good, of

$$
E_{t} m_{t+1} w_{t+1}
$$

where

$$
\mathrm{m}_{\mathrm{t}+1} \equiv \beta\left[\partial \mathrm{U}_{\mathrm{t}+1} / \partial \mathrm{c}_{\mathrm{t}+1}\right] /\left[\partial \mathrm{U}_{\mathrm{t}} / \partial \mathrm{c}_{\mathrm{t}}\right]
$$

is the state-specific marginal rate of substitution between date $t$ and $t+1$. Marginal utilities in (3.2) are given by

$$
\partial U_{t} / \partial c_{t}=\left(c_{t}-\gamma c_{t-1}\right)^{-\alpha}-\beta \gamma E_{t}\left(c_{t+1}-\gamma c_{t}\right)^{-\alpha} \text {. }
$$

The requirement that marginal utility be positive in all states places additional restrictions on the preference parameters and the process for consumption that we return to in the next section. 
Nominal assets, like currencies, are priced analogously. An asset yielding a stochastic flow of domestic currency $w_{t+1}$ at date $t+1$ is worth, in date-t units of the same currency,

$$
E_{t} n_{t+1} w_{t+1}
$$

where $\mathrm{n}_{\mathrm{t}+1} \equiv \mathrm{m}_{\mathrm{t}+1}\left(\mathrm{p}_{\mathrm{t}} / \mathrm{p}_{\mathrm{t}+1}\right)$ is the nominal marginal rate of substitution and $p_{t}$ is the price of the good in units of domestic currency.

Now consider the value of a forward contract. One side of the contract pays one unit of foreign currency next period in all states. This unit is equivalent in value to a stochastic payoff $s_{t+1}$ of domestic currency, which has value

$$
E_{t} n_{t+1} s_{t+1} \text {. }
$$

The other side of the contract pays $f_{t}$ units of the domestic currency in all states at date $t+1$. Its value is $f_{t} E_{t} n_{t+1}$. In equilibrium both sides must have the same value, so

$$
f_{t} / s_{t}=E_{t}\left[n_{t+1}\left(s_{t+1} / s_{t}\right)\right] / E_{t} n_{t+1} .
$$

Since the expectation of a product is the product of the expectations plus their covariance, we have

$$
f_{t} / s_{t}=E_{t}\left(s_{t+1} / s_{t}\right)+\operatorname{Cov}_{t}\left[n_{t+1},\left(s_{t+1} / s_{t}\right)\right] / E_{t} n_{t+1} .
$$

The second term we define as the risk premium. This term, which corresponds to $\mathrm{q}_{\mathrm{t}}$ in equation (2.4), can vary through time and in principle might account for departures from the unbiasedness hypothesis. In the theoretical economy equation (3.3) defines $\mathrm{f} / \mathrm{s}$ as a function of the current state of the economy. The essential characteristic of states with respect to asset pricing is that they determine the conditional distribution -- the row of the transition matrix $\Pi$-- with which the conditional moments in (3.3) are computed. 
Two special cases of (3.3) have received attention in the literature. One was motivated by Siegel (1972), whose work led to the suggestion that the theory produces nonzero risk premiums even when the representative aggregate consumer is risk-neutral $(\alpha=0)$. Subsequent work has found this term too small to account for empirical departures from the unbiasedness hypothesis. A second special case of additive separability $(\gamma=0)$ has received much closer attention. Studies by Cumby (1988) and Hansen and Hodrick (1983) suggest, however, that it too fails to account for the evidence. We verify each of these conclusions for our economy in the next section and proceed to examine nonzero values of the habit persistence parameter $\gamma$.

\section{Parameter values}

Our goal is to compare the statistical properties of the theoretical economy to those of the data. These properties depend, in general, on the parameters that describe the law of motion for the multivariate Markov process of $\{x, y, z\}$ and on the preference parameters $\{\alpha, \beta, \gamma\}$. Given values for each, we can compute the implied moments for spot and forward exchange rates from (3.3). We can compute, in particular, the standard deviation of the risk premium in (3.3) and compare it to our estimated lower bound of the standard deviation of expected excess returns from currency speculation. In principle the model can produce a wide range of behavior for forward rates, depending on the values of the model's many parameters. We impose some discipline on the choice of parameter values by estimating the Markov chain from U.S. data and imposing restrictions on the set of permissible preference parameters.

We estimate the transition matrix for the Markov chain from monthly time 
series for aggregate consumption, the price level, and spot exchange rates. The consumption series is U.S. nondurables and services, excluding clothing and medical care, and is measured on a per-capita basis. Blinder and Deaton (1985) argue that this measure of consumption is closer to the theoretical ideal of a flow of services, as opposed to expenditures, than measures that include consumer durables and the two excluded components. The implicit assumption with respect to durables is that their effect on utility is seperable from that of nondurables and services. The price level is the implicit deflator for the consumption series. The exchange rate is the Canadian dollar rate. Our analysis was also carried out using the British Pound with little effect on the model's properties. As we will see, the most important element of the model is the effect of habit persistence on the intertemporal marginal rate of substitution, which is independent of the behavior of the spot rate.

We specify the state space so that each variable -- consumption growth, inflation, and the rate of depreciation -. assumes two values, high and low. The value of the random variable in each state is computed as the mean over the historical occurrences of high and low, respectively, with high and low defined as above or below its sample mean. The two-state specification for each variable implies eight states for the Markov chain describing the evolution of the three state variables. The transition probabilities are estimated by maximum likelihood. If $n_{i j}$ is the number of times in the data that the economy passed from state $i$ in one period to state $j$ in the subsequent period, then our estimator of $\pi_{i j}$ is $n_{i j} / \Sigma_{k} n_{i k}$.

In Table 4 we report sample moments from the data and population moments from the theoretical economy based on the estimated eight-state Markov chain. 
The two are very similar, which suggests that the Markov chain provides a good approximation to the actual multivariate process, at least for these properties of the data. In addition, the population mean and standard deviation of the expected rate of depreciation $d$ are -0.0019 and 0.0026 , respectively, which are close to what we estimated in Tables 1 and 3 .

In selecting values for preference parameters we follow a strategy similar to Mehra and Prescott (1985) and Constantinides (1990). We are interested in whether there exist plausible values of $\{\alpha, \beta, \gamma\}$ for which the standard deviation of the theoretical risk premium is at least as great as the estimated lower bound reported in Table 3 . The set of permissible values is restricted as follows. (i) The discount factor $\beta$ is required to lie between zero and one. (ii) The curvature parameter $\alpha$ is restricted to lie in the interval $[0,10]$. Although there has been some debate on this point, we feel that larger values of $\alpha$ imply unreasonably strong aversion toward risk. (iii) The stochastic process for consumption and the preference parameters guarantee that $c^{*}$ and marginal utility are positive in all states. The former implies, with our estimated Markov chain, that $\gamma<0.9962$, the smallest consumption growth rate. The latter places more complex restrictions on preferences. (iv) The unconditional mean of price of a riskfree nominal bond, given by the conditional expectation of $n$, is restricted to lie within one standard deviation of the mean price of one-month U.S. treasury bills over the post Bretton Woods period, a range of 0.98 to 1.00 . This last condition turns out to be particularly restrictive. Without it, the model can account for all of the variability of expected excess returns. 


\section{Population moments in the theoretical economy}

In this section and the next we examine properties of forward exchange rates in the theoretical economy. Here we examine population moments -exact moments computed from the stochastic structure of the theoretical economy. In Section 6 we consider the sampling variability that arises when these moments are estimated from finite data sets.

In Table 6 we report the mean and standard deviation of the expected return, or risk premium, in our theoretical economy with five different parametrizations. In the first four we use the estimated eight-state Markov chain; the preference parameters $\{\alpha, \beta, \gamma\}$ are chosen to illustrate their effects on the forward risk premium. The fifth experiment uses the same preference parameters as the fourth, but introduces a modification to the Markov chain.

Examples (a) and (b) serve as benchmarks in that preferences are additively separable over time $(\gamma=0)$. Example (a) further restricts the representative agent to be risk neutral $(\alpha=0)$ and indicates the extent to which the "convexity term", or conditional covariance between returns and the inverse of inflation, contributes to the variability of the theoretical risk premium. Note that in both cases the standard deviation of $q$ is far below what we observe in the data. With risk neutrality the variability of the risk premium is several hundred times smaller than our estimated lower bound in Table 3. With additive separability and risk aversion the difference is a factor of about fifty, even though the coefficient of relative risk aversion is 10 (the largest value we consider). These calculations verify for this economy what other studies have concluded: expected returns associated with 
risk-neutral or additively-separable preferences are not nearly variable enough to account for observed asset returns. With additive separability we can generate greater variability of expected returns with extremely large values of $\alpha$, the coefficient of relative risk aversion. But such values not only conflict with one's intuition about reasonable behavior toward risk, they also imply much larger mean expected returns than we see in the data. Thus, the examples imply that without nonseparabilities the representativeagent framework is unable to account for the observed behavior of forward rates.

With habit persistence the economy produces greater variability in the risk premium. As we see in Figure 1, the standard deviation of the risk premium $q$ is increasing in $\gamma$. Examples (c) and (d) illustrate two values for the habit persistence parameter. In example (c) we choose $\gamma$ in the interval $(0,0.5]$ to maximize the standard deviation of the risk premium subject to the four restyrictions noted earlier; in example (d) we extend the interval to $(0,1)$. Note that durability of consumption, represented by negative values of $\gamma$, is not helpful in this respect. Figure 1 shows that negative values generate even less variability in the risk premium than we had with additively separable preferences. Nevertheless, the values of habit persistence reported in Table 6 are insufficient to account for the variability evident in the data. With moderate habit persistence [example (c) ] we account for about ten percent of the standard deviation reported in Table 3, and with extreme habit persistence [example (d)] we account for about half. In both cases the mean of the risk premium increases with the amount of habit persistence employed, but is small enough to allow the risk premium to assume both positive and negative values. 
Our final example illustrates the effects on our calculations of introducing an extreme state that occurs with small probability. The so-called "peso problem" has attracted a lot of attention in international finance, starting with Krasker (1980), where the possibility of large, infrequent changes in currency values is a fact of life. This example illustrates a point made by Rietz (1988) with regard to the equity premium: modifications of the stochastic structure that have little or no effect on the unconditional distribution can have large effects on asset prices and returns. Example (e) provides a stylized example of this phenomenon using the same preference parameters as example (d). In selecting the extreme state we note that, in our data set, the rate of change of the U.S.-Canadian exchange rate has been skewed towards appreciation of the U.S. dollar, with four episodes of monthly appreciation greater than 3 percent. Since we are interested in the possibility that agents placed positive probability on events more extreme than those that occurred, we choose an extreme state with a rate of appreciation of 9 percent, which is somewhat higher than the largest value observed in our sample ( 6 percent). Thus the Markov chain has twelve states: high and low for consumption growth and inflation, and low, high, and very high for changes in the spot rate. The transition probabilities are estimated from the data, using the four large appreciations as observations of the extreme state.

We find that the extreme state has a substantial effect on the variability of risk premiums in the model, raising their standard deviation from approximately 1.7 percent annually to about 2.6 percent. The latter is still about one-third below our lower bound, so if the peso problem is to account for the behavior of forward prices we would have to introduce a more extreme state. More generally this example illustrates a point made by Rietz 
(1988) in a different context: that changes in the conditional distribution which leave the unconditional distribution approximately unchanged can have a large influence on the behavior of asset prices and returns. Since conditional probabilities are difficult to estimate from short datasets, we think their potential influence is something that must be considered. In the next section we see that the extreme state has a larger effect on the sampling variability of the economy than on its population moments.

We conclude that an economy featuring habit persistence can account for a great deal more of the variability of expected returns from currency speculation than one based on time-additive preferences. In this sense non-separable preferences are useful. Nevertheless, there are no permissible values of the preference parameters for which we account for more than two thirds of the estimated standard deviation of expected returns. This conclusion also holds when we allow lags of two or three periods in the habit formation process. We can, however, account for all of the variability if we loosen some of the constraints we have imposed on the permissible set of parameters. This is easily done by, for example, allowing riskfree interest rates to differ substantially from the data or by permitting values that imply negative marginal utility in some states. We can thus account for the variability of the risk premium by allowing the model to be counterfactual in other dimensions. We prefer to limit the range of permissible parameter values and claim only partial success for habit persistence.

\section{Sampling variability in the artificial economy}

The large standard deviation of the expected return from currency speculation is among the established empirical features of spot and forward 
exchange rates. Another is the inverse correlation between expected rates of depreciation and expected returns that is implicit in the regression coefficients of Table 2: four of the five estimates of $b_{2}=1-b_{1}$ are negative. In this section we ask whether the risk premium in our artificial economy produces regression parameters similar to those reported in Table 2. We find that population values of $b_{2}$ are generally not negative. But given the sampling variability of the estimates in Table 2, a more natural question might be whether negative values occur with significant probability. We answer this question by conducting a sampling experiment along lines suggested by Gregory and Smith (1990).

In each experiment we generate 1000 artificial data sets of 148 observations (the same number used in Table 2), and estimate equation (2.6) for each dataset. This gives us 1000 estimates of $b_{2}=1-b_{1}$. We record the number of the rejections of the unbiasedness hypothesis (either $a_{1}=b_{1}=0$ or $b_{1}=0$ ) and the number of negative estimates of $b_{2}$. From the latter we estimate the density function for $b_{2}$ by nonparametric methods. We use $a$ quartic kernal and variable window width, as described by Silverman (1986). From the estimated density we compute the probability (prob-value) of a negative estimate of $b_{2}$ in the theoretical model. A high prob-value indicates that the model produces negative estimates with enough frequency to provide a reasonable correspondence with regression coefficients estimated with real data.

Our findings for the five examples of Table 6 and one additional experiment are summarized in Table 7 and Figures 2 and 3 . We see that for the risk-neutral and additively-separable cases the population value of $b_{2}$ is very close to one, the value implied by the unbiasedness hypothesis. Furthermore, neither of these examples produce enough variation in expected 
returns either to reject the unbiasedness hypothesis or to generate many negative values of $b_{2}$. The implication is that there is insufficient sampling variability in these economies to reconcile the artificial economy estimates of $b_{2}$ with the data-based estimates in Table 2. The reason, clearly, is that the standard deviation of the risk premium is much too small, as saw in Table 6.

Experiments (c) and (d) verify that extreme habit persistence is necessary to generate results that are substantially at odds with the unbiasedness hypothesis. Note that example (c), which has greater variability of the risk premium than examples (a) or (b), produces fewer rejections of the unbiasedness hypothesis. The reason, interestingly, is that the standard error of the least squares estimate of $b_{2}$ declines as the standard deviation of the risk premium rises (see Figure 2). Consequently we do not observe frequent rejections of the null hypothesis or negative $b_{2} s$.

Experiment (d) shows that as the standard deviation of the risk premium increases (with increasing habit persistence) the regression results tend towards rejection of the null hypothesis. We obtain a population value of $b_{2}$ $=0.76$ and witness a corresponding leftward shift of the estimated density function. We also observe more rejections of the null hypothesis than can be attributed to experimental randomness at the five percent level. (This number is approximately fifty; a 95 percent confidence interval is approximately $[36,64]$.$) Again, the density estimates indicate that the$ standard error of the regression declines substantially as the risk premium becomes more variable, and we still observe few negative values for $b_{2}$.

Two experiments with an extreme state, motivated by the popular "peso 
problem," are more successful in this regard. Experiment (e) is the peso problem from Table 6. We also introduce an additional example, labelled (f), in which the Monte Carlo experiment is performed conditional on the extreme state not occurring. This can be viewed as 1000 selected realizations of our data generating process in which the extreme state never occurred. The essence of the peso problem is that in small samples extreme states are not realized in accordance with the probabilities that agents assign them. It is clear that a simulation like experiment (e) cannot adequately capture this effect since, in 1000 replications, the extreme state will be realized with frequency very close to its unconditional probability (2 percent in this economy). By considering only realizations in which no extreme states occur, we obtain an experiment that is closer in spirit to what has generally been considered the small sample peso problem.

With the exception of this selection rule, experiments (e) and ( $f$ ) are identical. Note that (e) features many more rejections of the unbiasedness hypothesis than the first four experiments, although not substantially more negative values for $b_{2}$. But in experiment (f) the unbiasedness hypothesis is almost always rejected and, for the first time, we observe a significant number of negative $b_{2} s$. Figure 3 shows that the density has shifted to the left, with approximately 30 percent of its mass over the negative halfline. The experiment is thus consistent with the view that the departures from unbiasedness observed in data are related to peso problems.

\section{Variability of the intertemporal marginal rate of substitution}

We have seen that habit persistence helps to account for the variability of expected returns from currency speculation, just as it helped to account 
for expected excess returns on equity. In this sense the two phenomena are related. In this section we make the relation between the two more precise, using tools developed by Hansen and Jagannathan (1990) and Shiller (1982).

Consider, as we did in Section 2, the returns on a balanced portfolio, where by balanced we mean a portfolio financed by going short in one asset and investing the same amount in another asset. Since the amounts are the same, the price of the portfolio is zero and the net returns $x_{t+1}$ (measured in dollars) satisfy the relation

$$
E_{t} n_{t+1} x_{t+1}=0 \text {, }
$$

where $\mathrm{n}$ is the nominal marginal rate of substitution, defined in section 3 . This relation holds in our economy [recall (3.2)] and also, as Hansen and Jagannathan show, in a much wider class.

We can easily show that this relation implies a lower bound on the standard deviation of $\mathrm{n}$. Since (7.1) holds for conditional moments it holds unconditionally as well, and

$$
0=(E n)(E x)+\operatorname{Cov}(n, x)
$$

Since $\mathrm{n}$ is a positive random variable, and correlations are less than one in absolute value, we establish

$$
\sigma_{n} / E n \geq|E x| / \sigma_{x}
$$

where $\sigma_{z}$ denotes the standard deviation of the random variable $z$. In words, the absolute value of the "Sharpe ratio" of the balanced portfolio, $|E x| / \sigma_{x}$, provides a lower bound on the ratio of the standard deviation of the marginal rate of substitution to its mean. And since the mean is close to one (monthly rates of interest are small) this provides an approximate lower bound on $\sigma_{n}$. 
A useful interpretation of the equity premium puzzle is that it requires a larger standard deviation of $n$ than we get with additively seperable preferences. Breen, Glosten, and Jagannathan (1989) report that the return from a balanced portfolio constructed by financing equity investment with short-term riskfree debt (treasury bills in their example) had a mean of 0.80 percent per month and a standard deviation of 5.77 percent, for a Sharpe ratio of 0.14 . (These numbers are from their Table I, for the equallyweighted NYSE index from August 1970 to December 1986.) Thus the estimated lower bound on the standard deviation of $\mathrm{n}$ is about 0.14 . We see in Table 8 , example (b), that our economy with additively separable preferences and risk aversion of 10 has a standard deviation less than one-third this amount, so the equity premium is not explained by this theory.

The Sharpe ratios reported in Table 4 for currency speculation have, if anything, stronger implications. They range from 0.09 for the deutschemark to 0.36 for Japan, which implies, again, substantial variability of the intertemporal marginal rate of substitution. Figure 4 plots the standard deviation of $\mathrm{n}$ against the habit persistence parameter $\gamma$, and we see that the lower bound for the Yen implies a value of $\gamma$ of at least 0.58 . Thus we see that both the equity premium and returns from currency speculation imply greater variability of the marginal rate of substitution than we find with time-additive preferences and moderate degrees of risk aversion. Moreover, this is clearly a real -- as opposed to nominal -- phenomenon: the standard deviations of real and nominal intertemporal marginal rates of substitution ( $m$ and $n$ in Section 3) are identical for the level of accuracy reported in Table 8 (three or four significant figures). Thus the variability in Table 8 of the nominal marginal rate of substitution is almost entirely due to 
variation in consumption growth, not inflation, and the nominal character of currencies is not an important issue in the analysis.

\section{Habit persistence reconsidered}

A broader question than we have confronted so far is whether habit persistence is a persuasive explanation for expected returns from currency speculation, or for asset returns more generally. We have seen that with reasonable bounds on parameter values, habit persistence accounts for up to two thirds of the estimated standard deviation of expected returns, a substantial improvement over the theory with time-additive preferences. Other work, notably Abel (1990), Constantinides (1990), Ferson and Constantinides (1989), and Nason (1988), has documented the ability of related theories to account for the large average excess return of equity over short-term riskfree assets.

Nevertheless, a number of recent studies argue that habit persistence has other quantitative implications that conflict with observed properties of the data. Among them, Dunn and Singleton (1986), Eichenbaum, Hansen, and Singleton (1988), Gallant and Tauchen (1989), Gallant, Hansen, and Tauchen (1989), and Heaton (1989) report negative estimates of habit persistence parameters, indicating that consumption exhibits durability rather than habit formation. Apparently some properties of the data suggest durability, while others, notably the equity premium, suggest habit formation. In the articles just cited, durability dominates because the mean equity premium is not one of the more precisely estimated moments in the data, and the estimation methods place greater weight on moments that are estimated more precisely. 
One of these moments is the autocorrelation of consumption growth rates. Consumption growth rates in monthly data have an autocorrelation of about -0.2 (see Table 3). Since the theory implies that discounted marginal utilities are martingales, this is inconsistent with additively separable preferences. The articles just cited reconcile the martingale property with the data by introducing durability into preferences (a negative value of $\gamma$ in equation (3.1)). Negative autocorrelation of consumption growth rates implies the opposite of habit formation and thus poses a challenge to asset pricing theories driven by habits. Perhaps the best response to this challenge is to point to measurement error in consumption data. A careful look at the procedures followed by the Commerce Department in constructing monthly consumption figures suggests that sampling variability and seasonal adjustment are likely sources of systematic, and possibly autocorrelated, measurement error; see, for example, Wilcox (1988). Ferson and Constantinides (1989) make this argument against choosing parameters to fit consumption moments, and Gregory and Wirjanto (1990) show that modest amounts of serially correlated measurement егror in consumption growth rates can have substantial effects on estimated preference parameters.

A related issue is whether the habit persistence parameter used in some of our examples is implausibly large. Our choice of $\gamma=0.85$ in examples (d) and (e) implies very strong habit formation. This value is very close, however, to estimates by Ferson and Constantinides (1989) using moments other than autocorrelations of consumption growth and asset returns. They report estimates of $\gamma$ in the range of 0.79 to 0.95 for quarterly and annual data.

Another set of moments can be categorized as auto- and crosscorrelations of asset returns. We know, for example, that short rates are 
positively autocorrelated, that excess returns on equity are serially uncorrelated, and that excess returns on equity are negatively correlated with lagged interest rates. Test statistics for models estimated from these moments often imply that first-order conditions with habit persistence do not account for these properties of the data. In Gallant, Hansen, and Tauchen (1989), for example, it appears that habit formation does not account for the predictability of real returns on equity and treasury bills. A similar phenomenon arises in our application. We reported in Table 1 that one of the regularities of forward and spot exchange rates is that the forward premium, $f_{t}{ }^{-s} t$, is positively autocorrelated. The first-order autocorrelations range from 0.208 for the United Kingdom to 0.812 for Japan. In our theoretical economies (see Table 8 ) these numbers are considerably smaller, and typically negative. It thus appears that while the representative agent theory of asset pricing with habit formation can account for the variability of the intertemporal marginal rate of substitution, it does not account for all of the dynamic properties of the data.

\section{Last thoughts}

We have shown that habit persistence raises the variability of the standard deviation of expected returns from currency speculation to about one-half to two-thirds its estimated value in the data. Without habits the theory accounts for less than five percent of the standard deviation, so habit formation is clearly useful in this respect. This finding is to a large extent a function of our insistence that the parameters not have implications that conflict with other features of the data. Without these restrictions the theory can generate as much variability as we see in the data. We have also argued that the puzzle with forward and spot exchange 
rates is similar to the equity premium puzzle, since both require large standard deviations of the intertemporal marginal rate of substitution. Finally, our analysis suggests that extreme events, even those with small probabilities, can have large effects on the behavior of forward prices on currencies. This point was made by Rietz (1988) in the context of the equity premium. We think it makes a better story for currencies, since nominal variables have historically been much more prone to large changes than real variables. 


\section{References}

Andrew Abel, "Asset prices under habit formation and catching up with the Joneses," American Economic Review, 80 (May 1990), 38-42.

David Backus, Allan Gregory, and Stanley Zin, "Risk premiums in the term structure: evidence from artificial economies, "Journal of Monetary Economics, 24 (November 1989), 371-399.

Richard Baillie, Robert Lippens, and Patrick McMahon, "Testing rational expectations and efficiency in the foreign exchange market," Econometrica, 51 (1983), 553-364.

Ravi Bansal, "Can nonseparabilities explain exchange rate movements and risk premia?" unpublished manuscript, Carnegie Mellon University, March 1990.

John Bilson, "The 'speculative efficiency' hypothesis," Journal of Business, $54(1981), 435-452$.

John Bilson, "Technical' currency trading," unpublished manuscript, September 1989.

Paul Boothe and David Longworth, "Foreign exchange market efficiency tests: implications of recent findings, "Journal of International Money and Finance, 5 (1986), 135-152.

William Breen, Lawrence Glosten, and Ravi Jagannathan, "Economic significance of predictable variations in stock index returns, "Journal of Finance, 44 (December 1989), 1177-1189.

Fabio Canova, "Is there a risk premium puzzle in foreign exchange markets?" unpublished manuscript, Brown University, October 1989.

George Constantinides, "Habit formation: A resolution of the equity premium puzzle" Journal of Political Economy, 98 (June 1990), 51-543.

Robert Cumby, "Is it risk? Explaining deviations from uncovered interest parity," Journal of Monetary Economics, 22 (September 1988), 279-299.

Robert Cumby and Maurice Obstfeld, "International interest-rate and price-level linkages under flexible exchange rates: A review of recent evidence," in Exchange Rates: Theory and Practice, ed. J.F.O. Bilson and R. Marston, Chicago: University of Chicago Press, 1984.

Kenneth Dunn and Kenneth Singleton, "Modeling the term structure of interest rates under nonseparable utility and durability of goods, "Journal of Financial Economics, 17 (1986), 27-55.

Martin Eichenbaum, Lars Hansen, and Kenneth Singleton, "A time series analysis of representative agent models of consumption and leisure choice under uncertainty," Quarterly Journal of Economics, 103 (February 1988), 51-78.

Charles Engel, "On the foreign exchange risk premium in a general equilibrium model," unpublished manuscript, University of Virginia, April 1990.

Robert Engle, "Autoregressive Conditional Heteroskedasticity with Estimates 
of the Variance of U.K. Inflation," Econometrica, 50 (November 1982), 987-1007.

Eugene Fama, "Forward and spot exchange rates," Journal of Monetary Economics, 14 (November 1984), 319-338.

Wayne Ferson and George Constantinides, "Habit persistence and durability in aggregate consumption: Empirical tests," unpublished manuscript, University of Chicago, November 1989.

Jeffrey Frankel and Kenneth Froot, "Forward discount bias: Is it an exchange risk premium?" Quarterly Journal of Economics, 104 (February 1989), $139-161$.

Ronald Gallant, Lars Hansen, and George Tauchen, "Using conditional moments of asset payoffs to infer the volatility of intertemporal marginal rates of substitution," unpublished manuscript, September 1989; forthcoming Journal of Econometrics.

L. G. Godfrey, "Testing for higher order serial correlation in regression equations when the regressors include lagged dependent variables," Econometrica, 46 (1978), 1303-1310.

Allan Gregory and Thomas McCurdy, "Testing the unbiasedness hypothesis in the forward foreign forward exchange market," Journal of International Money and Finance, 3 (1984), 357-368.

Allan Gregory and Gregor Smith, "Calibration as testing," Queen's University Discussion Paper No 725, 1990.

Allan Gregory and Gregor Smith, "Calibration as estimation," Econometric Reviews, forthcoming 1989.

Allan Gregory and Tony Wirjanto, "The effect of sampling error on the time series behavior of consumption data: A comment," unpublished manuscript, May 1990.

Sanford Grossman, Angelo Melino, and Robert Shiller, "Estimating the continuous-time consumption-based asset-pricing model, "Journal of Business and Economic Statistics, 5 (1987), 315-327.

Lars Hansen and Robert Hodrick, "Forward exchange rates as opt imal predictors of future spot rates: an econometric analysis," Journal of Political Economy, 88 (1980), 829-853.

Lars Hansen and Robert Hodrick, "Risk averse speculation in the forward foreign exchange market: An econometric analysis of linear models," in J. Frenkel, ed., Exchange Rates and International Macroeconomics, Chicago: University of Chicago Press for the NBER, 1983.

Lars Hansen and Ravi Jagannathan, "Implications of security market data for models of dynamic economies," Institute for Empirical Macroeconomics Discussion Paper 29, Federal Reserve Bank of Minneapolis, April 1990.

John Heaton, "An empirical investigation of asset pricing with temporally dependent preference specifications," unpublished manuscript, M.I.T., December 1988. 
Robert Hodrick, The Empirical Evidence on the Efficiency of Forward and Futures Foreign Exchange Markets, New York: Harwood Academic Publishers, 1987.

Robert Hodrick and Sanjay Srivastava, "An investigation of risk and return in forward foreign exchange," Journal of International Money and Finance, $3(1984), 1-29$.

Robert Hodrick and Sanjay Srivastava, "The covariation of risk premiums and expected future spot exchange rates," Journal of International Money and Finance, 5 (1986), S5-S22.

Ravi Jagannathan, "An investigation of commodity futures prices using the consumption-based intertemporal capital asset pricing model, "Journal of Finance, 40 (March 1985), 175-191.

Robert Korajczyk and Claude Viallet, "Equity risk premia and the pricing of foreign exchange risk, " unpublished manuscript, Northwestern University, May 1990.

William Krasker. "The 'peso problem' in testing the efficiency of forward exchange markets," Journal of Monetary Economics, 6 (1980), 276-296.

Karen Lewis, "Changing beliefs and systematic rational forecast errors with evidence from foreign exchange," American Economic Review, 79 (September 1989), 621-636.

Robert Lucas, "Asset prices in an exchange economy," Econometrica, 55 (November 1978), 1429-1445.

Robert Lucas, "Interest rates and currency prices in a two-country world," Journal of Monetary Economics, 10 (1982), 335-360.

Tiff Macklem, "Forward exchange rates in artificial economies," unpublished manuscript, University of Western Ontario, March 1988.

Nelson Mark, "On time-varying risk premia in the foreign exchange market: an econometric analysis," Journal of Monetary Economics, 16 (1985), 3-18.

Rajnish Mehra and Edward Prescott, "The equity premium: A puzzle," Journal of Monetary Economics, 15 (1985), 145-161.

James Nason, "The equity premium and time-varying risk. behavior, " unpublished manuscript, Board of Governors of the Federal Reserve System, February 1988.

Thomas Rietz, "The equity premium: A solution," Journal of Monetary Economics, 22 (1988), 117-131.

Robert Shiller, "Consumption, asset markets, and macroeconomic fluctuations, " Carnegie-Rochester Conference Series on Public Policy, 17 (1982), 203-238.

J.J. Siegel, "Risk, information, and forward exchange," Quarterly Journal of 
Economics, 86 (1972), 303-309.

B.W. Silverman, Density Estimation for Statistical and Data Analysis, London: Chapman and Hall, 1986.

Rene Stulz, "An equilibrium model of exchange rate determination and asset pricing with nontraded goods and imperfect information." Journal of Political Economy, 95 (1987), 1024-1040.

Suresh Sundaresan, "Intertemporally dependent preferences and the volatility of consumption and wealth, " Review of Financial Studies, 2 (1989), 73-89.

H. White, "A heteroskedasticity-consistent covariance matrix estimator and a direct test for heteroskedasticity," Econometrica, 48 (1980), 817-838.

David Wilcox, "What do we know about consumption?" unpublished manuscript, Board of Governors of the Federal Reserve System, June 1988. 


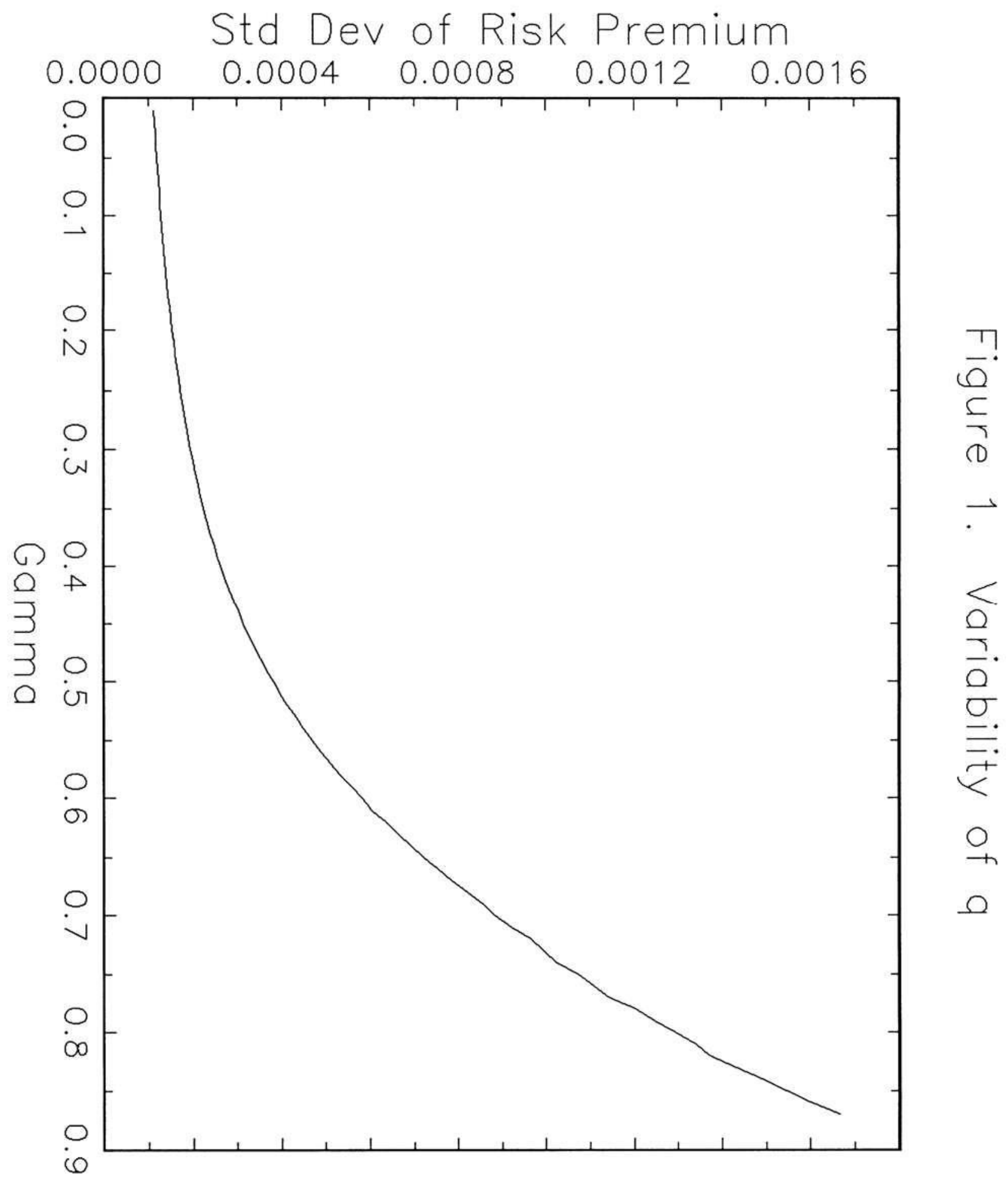




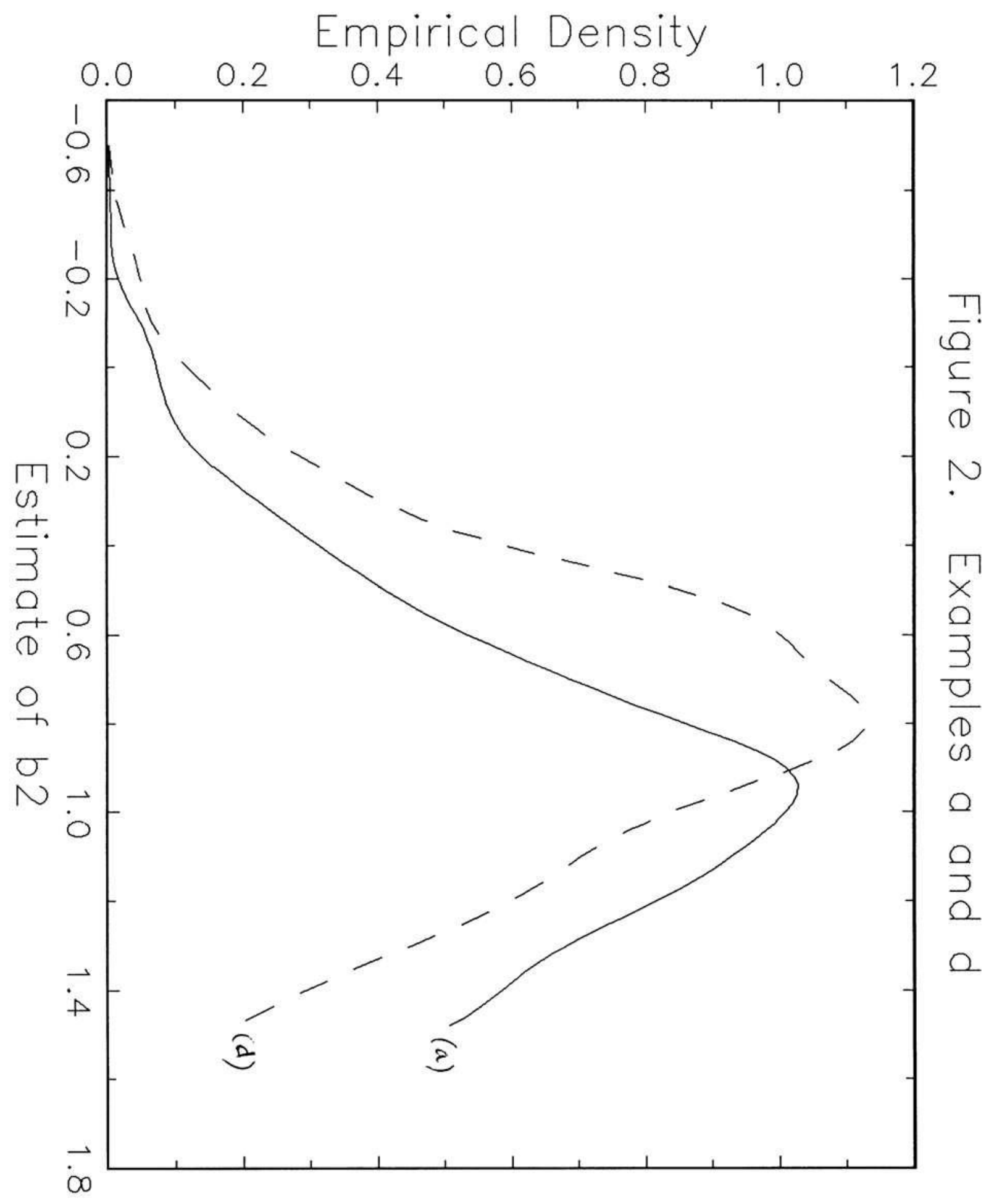




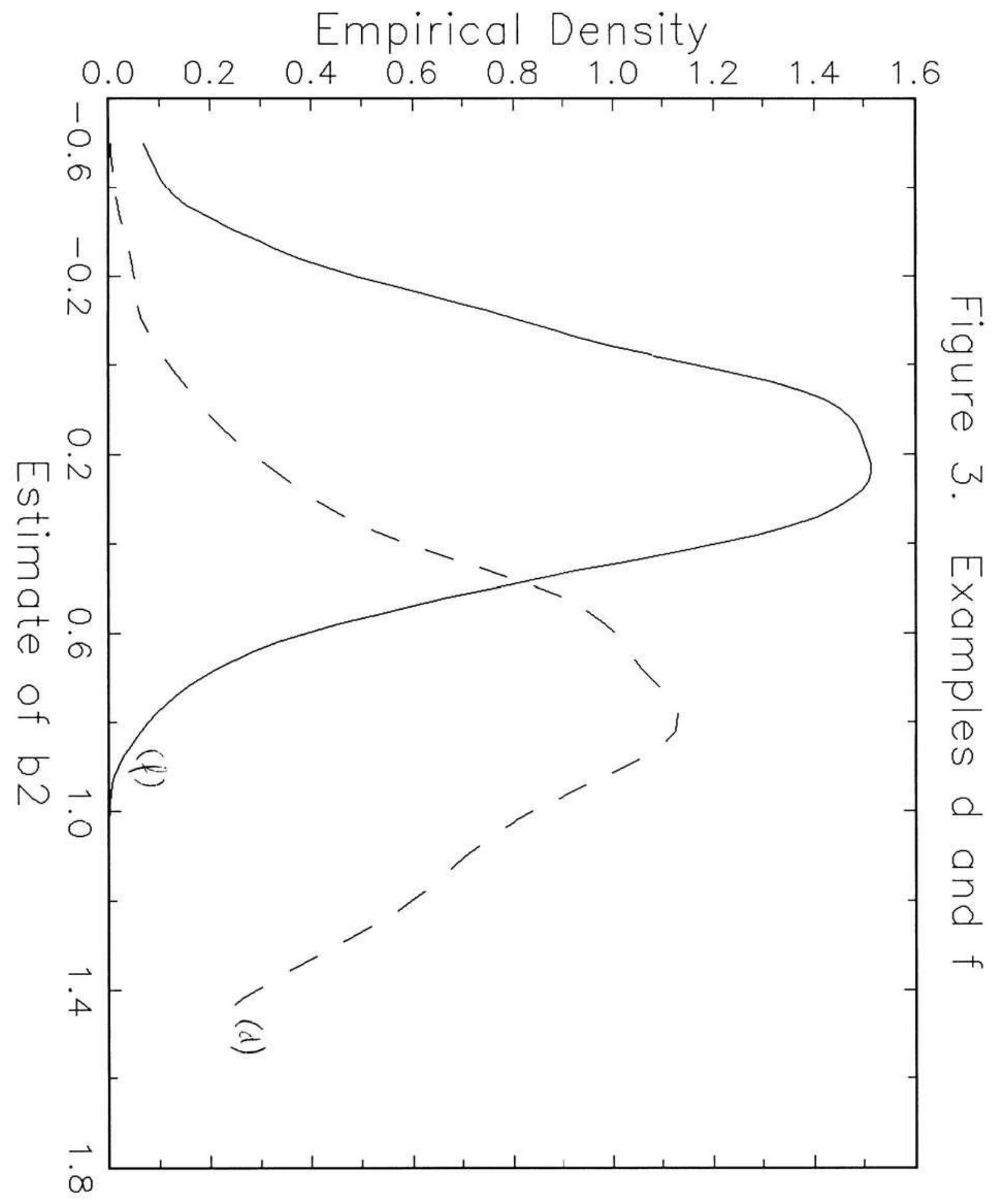


Figure 4. Variability of MRS

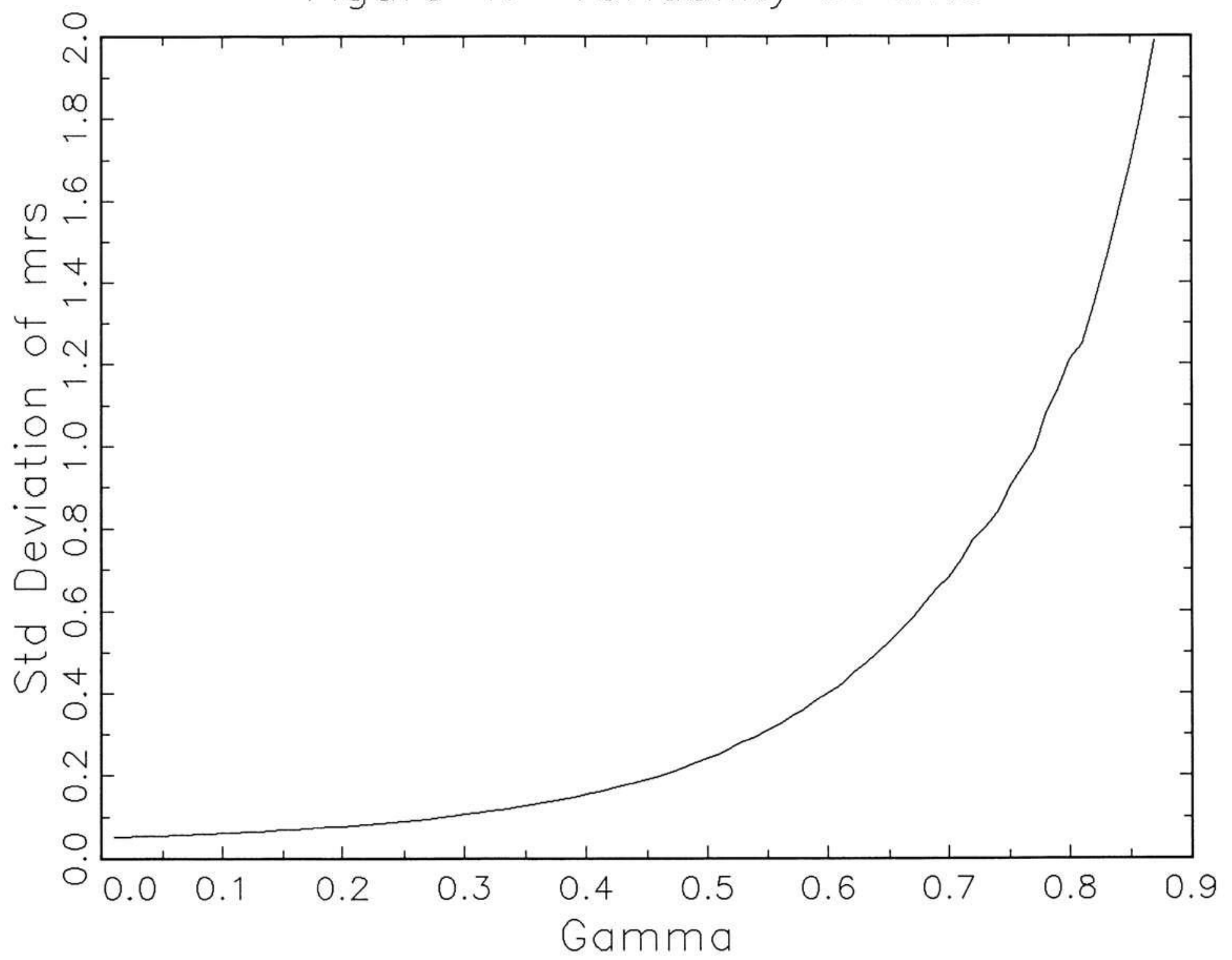


TABLE 1

PROPERTIES OF FORWARD AND SPOT EXCHANGE RATES

\begin{tabular}{|c|c|c|c|c|c|}
\hline \multirow[t]{2}{*}{ Statistic } & \multicolumn{5}{|c|}{ Country } \\
\hline & Canada & France & Germany & Japan & $\begin{array}{l}\text { United } \\
\text { Kingdom }\end{array}$ \\
\hline \multicolumn{6}{|c|}{ (a) $\left(f_{t}-s_{t+1}\right) / s_{t}$} \\
\hline mean & $\begin{array}{c}0.00121 \\
(0.00113)\end{array}$ & $\begin{array}{l}-0.00079 \\
(0.00395)\end{array}$ & $\begin{array}{c}0.00087 \\
(0.00420)\end{array}$ & $\begin{array}{l}-0.00190 \\
(0.00417)\end{array}$ & $\begin{array}{c}0.00110 \\
(0.00399)\end{array}$ \\
\hline std deviation & $\begin{array}{c}0.01357 \\
(0.00121)\end{array}$ & $\begin{array}{c}0.03296 \\
(0.00265)\end{array}$ & $\begin{array}{c}0.03338 \\
(0.00227)\end{array}$ & $\begin{array}{c}0.03316 \\
(0.00357)\end{array}$ & $\begin{array}{c}0.03270 \\
(0.00285)\end{array}$ \\
\hline autocorrelation & $\begin{array}{l}-0.075 \\
(0.056)\end{array}$ & $\begin{array}{l}-0.016 \\
(0.095)\end{array}$ & $\begin{array}{c}0.005 \\
(0.087)\end{array}$ & $\begin{array}{c}0.181 \\
(0.045)\end{array}$ & $\begin{array}{c}0.136 \\
(0.064)\end{array}$ \\
\hline \multicolumn{6}{|c|}{ (b) $\quad\left(s_{t+1}-s_{t}\right) / s_{t}$} \\
\hline mean & $\begin{array}{l}-0.00225 \\
(0.00104)\end{array}$ & $\begin{array}{l}-0.00168 \\
(0.00416)\end{array}$ & $\begin{array}{c}0.00231 \\
(0.00402)\end{array}$ & $\begin{array}{c}0.00462 \\
(0.00377)\end{array}$ & $\begin{array}{l}-0.00296 \\
(0.00380)\end{array}$ \\
\hline std deviation & $\begin{array}{c}0.01322 \\
(0.00124)\end{array}$ & $\begin{array}{c}0.03284 \\
(0.00273)\end{array}$ & $\begin{array}{c}0.03325 \\
(0.00228)\end{array}$ & $\begin{array}{c}0.03244 \\
(0.00341)\end{array}$ & $\begin{array}{c}0.03196 \\
(0.00286)\end{array}$ \\
\hline autocorrelation & $\begin{array}{l}-0.125 \\
(0.053)\end{array}$ & $\begin{array}{l}-0.054 \\
(0.086)\end{array}$ & $\begin{array}{l}-0.017 \\
(0.082)\end{array}$ & $\begin{array}{c}0.144 \\
(0.047)\end{array}$ & $\begin{array}{c}0.112 \\
(0.061)\end{array}$ \\
\hline \multicolumn{6}{|c|}{ (c) $\left(f_{t}-s_{t}\right) / s_{t}$} \\
\hline mean & $\begin{array}{l}-0.00104 \\
(0.00039)\end{array}$ & $\begin{array}{l}-0.00247 \\
(0.00091)\end{array}$ & $\begin{array}{c}0.00318 \\
(0.00049)\end{array}$ & $\begin{array}{c}0.00271 \\
(0.00092)\end{array}$ & $\begin{array}{l}-0.00185 \\
(0.00082)\end{array}$ \\
\hline std deviation & $\begin{array}{c}0.00162 \\
(0.00018)\end{array}$ & $\begin{array}{c}0.00397 \\
(0.00084)\end{array}$ & $\begin{array}{c}0.00215 \\
(0.00019)\end{array}$ & $\begin{array}{c}0.00329 \\
(0.00044)\end{array}$ & $\begin{array}{c}0.00329 \\
(0.00045)\end{array}$ \\
\hline autocorrelation & $\begin{array}{c}0.382 \\
(0.063)\end{array}$ & $\begin{array}{c}0.630 \\
(0.109)\end{array}$ & $\begin{array}{c}0.304 \\
(0.146)\end{array}$ & $\begin{array}{c}0.812 \\
(0.077)\end{array}$ & $\begin{array}{c}0.208 \\
(0.114)\end{array}$ \\
\hline
\end{tabular}

Notes: Forward and spot exchange rates, $f$ and s respectively, are expressed as dollars per unit of foreign currency. Data are month-end, July 1974 to October 1986, from Gregory and McCurdy (1984), updated from the International Monetary Market Annual Yearbook of the Chicago Mercantile Exchange, various issues. Numbers in parentheses are standard errors; they were computed by generalized method of moments (GMM) and are robust to heteroskedasticity and autocorrelation of the residuals of the moment conditions (Hansen, 1982). 
TABLE 2

ESTIMATED REGRESSION LINES

$$
\left(f_{t}-s_{t+1}\right) / s_{t}=a_{1}+b_{1}\left(f_{t}-s_{t}\right) / s_{t}+u_{t+1}
$$

\begin{tabular}{cccccc}
\hline \multirow{2}{*}{ Statistic } & \multicolumn{5}{c}{ Country } \\
\cline { 2 - 5 } & Canada & France & Germany & Japan & $\begin{array}{l}\text { United } \\
\text { Kingdom }\end{array}$ \\
& & & & & \\
& & & & & \\
$\mathrm{a}_{1}$ & 0.00363 & 0.00110 & -0.00375 & -0.00918 & 0.00611 \\
$\mathrm{~b}_{1}$ & $(0.00113)$ & $(0.00548)$ & $(0.00339)$ & $(0.00460)$ & $(0.00379)$ \\
$\mathrm{s}$ & 2.322 & 0.766 & 1.453 & 2.680 & 2.703 \\
AR4 & $(0.333)$ & $(1.173)$ & $(0.773)$ & $(0.738)$ & $(0.748)$ \\
ARCH4 & 0.01309 & 0.03294 & 0.03335 & 0.03208 & 0.03157 \\
HET & 0.083 & 0.111 & 0.440 & 0.139 & 0.639 \\
& 0.591 & 0.020 & 0.000 & 0.316 & 0.327
\end{tabular}

Notes: The data are described in the notes to Table 1 . Numbers in parentheses are standard errors, computed by GMM. $\mathbf{s}$ is the standard error of the regression (the estimated standard deviation of $u$ ). AR4, ARCH4, and HET are the marginal significance levels for, respectively, lagrange multiplier tests for fourth order serial correlation (Godfrey, 1978) and fourth order autoregressive conditional heteroskedasticity (Engle, 1982), and for a cross product test for heteroskedasticity (White, 1980). 
TABLE 3

STANDARD DEVIATIONS OF EXPECTED DEPRECIATION AND EXCESS RETURNS: ESTIMATED LOWER BOUNDS

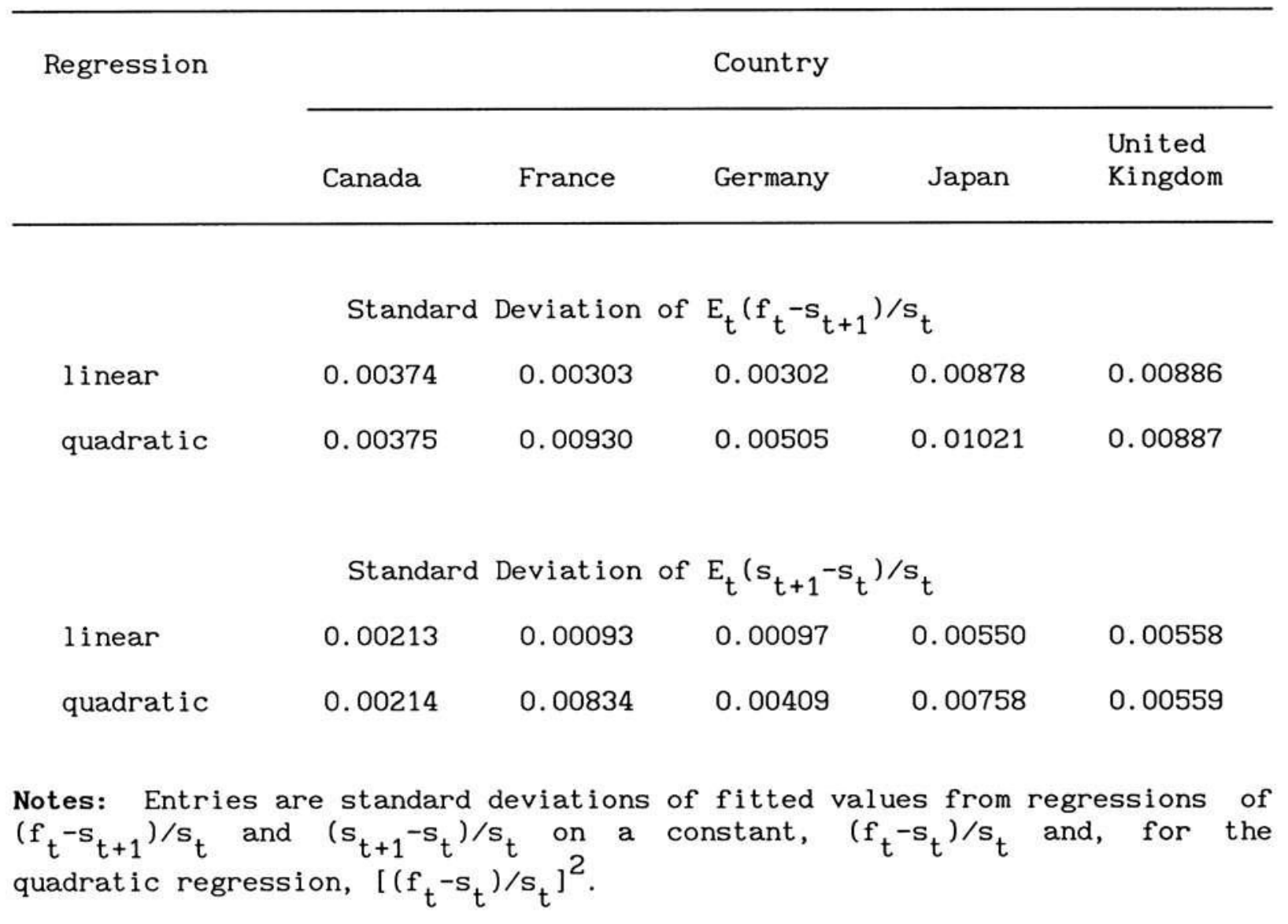


TABLE 4

PROPERTIES OF RETURNS FROM CURRENCY SPECULATION

\begin{tabular}{cccccc}
\hline \multirow{2}{*}{ Statistic } & \multicolumn{3}{c}{ Country } \\
\cline { 2 - 5 } & Canada & France & Germany & Japan & $\begin{array}{l}\text { United } \\
\text { Kingdom }\end{array}$ \\
& & & & & \\
mean & 0.00345 & 0.00488 & 0.00312 & 0.01119 & 0.00799 \\
std deviation & 0.01318 & 0.03261 & 0.03325 & 0.03126 & 0.03172 \\
Sharpe ratio & 0.262 & 0.150 & 0.094 & 0.358 & 0.252
\end{tabular}

Notes: Returns are based on the investment strategy described in the text. The Sharpe ratio is the ratio of the mean to the standard deviation of the return. 
TABLE 5

MOMENTS IN THE DATA AND IN THE THEORETICAL ECONOMY

\begin{tabular}{|c|c|c|c|}
\hline & $\begin{array}{l}\text { Consumption } \\
\text { growth }\end{array}$ & Inflation & Depreciation \\
\hline \multicolumn{4}{|c|}{ Univariate moments } \\
\hline mean & $\begin{array}{l}1.0012 \\
1.0014\end{array}$ & $\begin{array}{l}1.0053 \\
1.0052\end{array}$ & $\begin{array}{l}0.9978 \\
0.9980\end{array}$ \\
\hline std deviation & $\begin{array}{l}0.0047 \\
0.0050\end{array}$ & $\begin{array}{l}0.0033 \\
0.0035\end{array}$ & $\begin{array}{l}0.0132 \\
0.0133\end{array}$ \\
\hline autocorrelation & $\begin{array}{l}-0.212 \\
-0.249\end{array}$ & $\begin{array}{l}0.556 \\
0.353\end{array}$ & $\begin{array}{l}-0.125 \\
-0.016\end{array}$ \\
\hline \multicolumn{4}{|c|}{ Cross correlations } \\
\hline $\begin{array}{l}\text { Consumption } \\
\text { Growth }\end{array}$ & 1.0 & $\begin{array}{l}-0.429 \\
-0.408\end{array}$ & $\begin{array}{r}-0.072 \\
0.024\end{array}$ \\
\hline Inflation & & 1.0 & $\begin{array}{r}-0.049 \\
0.017\end{array}$ \\
\hline \multicolumn{4}{|c|}{$\begin{array}{l}\text { Notes: For each pair of numbers the first is a sample moment computed from } \\
\text { the data and the second is a population moment from the theoretical economy. } \\
\text { The values from the artifical economy are functions of the estimated Markov } \\
\text { chain alone and do not depend on preference parameters. The consumption } \\
\text { series is from CITIBASE, nondurables plus services net of clothing and } \\
\text { medical care, divided by the civilian population. The price series is its } \\
\text { implicit deflator. The exchange rate series is the Canadian dollar. }\end{array}$} \\
\hline
\end{tabular}


TABLE 6

PROPERTIES OF RISK PREMIUMS IN THE THEORETICAL ECONOMY

\begin{tabular}{|c|c|c|}
\hline $\begin{array}{c}\text { Economy } \\
\text { (Parameter Values) }\end{array}$ & $\begin{array}{c}\text { Mean of } \\
\text { Risk Premium }\end{array}$ & $\begin{array}{l}\text { Standard Deviation } \\
\text { of Risk Premium }\end{array}$ \\
\hline \multicolumn{3}{|l|}{ United States (estimated) } \\
\hline no parameters. & 0.00121 & 0.00375 \\
\hline \multicolumn{3}{|l|}{ Risk neutrality (a) } \\
\hline$\alpha=0, \quad \beta=0.99, \quad \gamma=0$. & 0.00000 & 0.00001 \\
\hline \multicolumn{3}{|l|}{ Additive separability (b) } \\
\hline$\alpha=10, \quad \beta=0.99, \quad \gamma=0$. & 0.00000 & 0.00011 \\
\hline \multicolumn{3}{|l|}{ Habit persistence 1 (c) } \\
\hline$\alpha=10, \quad \beta=0.99, \quad \gamma=0.50$. & 0.00006 & 0.00038 \\
\hline \multicolumn{3}{|l|}{ Habit persistence 2 (d) } \\
\hline$\alpha=9, \quad \beta=0.60, \gamma=0.85$. & 0.00020 & 0.00146 \\
\hline \multicolumn{3}{|l|}{ Peso problem (e) } \\
\hline$\alpha=9, \quad \beta=0.60, \gamma=0.85$. & 0.00031 & 0.00217 \\
\hline
\end{tabular}

Notes: Properties of U.S. data are taken from Tables 1 (a) and 3, for the Canadian dollar. Properties in theoretical economies were calculated from equilibrium prices. Examples (a), (b), (c), and (d) use the 8-state Markov chain described in the text. Example (e) uses the 12-state chain, which incorporates an extreme state for the spot rate. The mean and standard deviation for the expected rate of depreciation in economy (e) are -0.0030 and 0.0028 , respectively. 
TABLE 7

PROPERTIES OF REGRESSIONS IN THE THEORETICAL ECONOMY

\begin{tabular}{|c|c|c|c|c|}
\hline \multirow{2}{*}{ Theoretical Economy } & \multicolumn{2}{|c|}{ Number of Rejections of } & \multirow{2}{*}{$\begin{array}{l}\text { Population } \\
\qquad b_{2}\end{array}$} & \multirow{2}{*}{$\begin{array}{c}\text { Negative } \\
\mathrm{b}_{2} \mathrm{~s}\end{array}$} \\
\hline & $a_{1}=b_{1}=0$ & $\mathrm{~b}_{1}=0$ & & \\
\hline Risk neutrality (a) & 72 & 69 & 1.000 & 11 \\
\hline Additive separability (b) & 68 & 71 & 1.005 & 10 \\
\hline Habit persistence 1 (c) & 63 & 69 & 1.000 & 9 \\
\hline Habit persistence 2 (d) & 98 & 87 & 0.761 & 17 \\
\hline Peso problem 1 (e) & 189 & 227 & 0.711 & 29 \\
\hline Peso problem 2 (f) & 981 & 940 & 0.711 & 223 \\
\hline
\end{tabular}

Notes: Parameter values for the theoretical economies are decribed in Table 6. Experiment ( $f$ ), described in the text, uses the same parameter values as experiment (e). Numbers of rejections are based on 1000 replications of the economy, each with 148 observations. Hypothesis tests are at the $\mathbf{5}$ percent significance level and are based on heteroskedasticity-consistent standard errors (White, 1980). Negative bas refer to the number of negative estimates in 1000 replications. 
TABLE 8

OTHER POPULATION MOMENTS IN THE THEORETICAL ECONOMIES

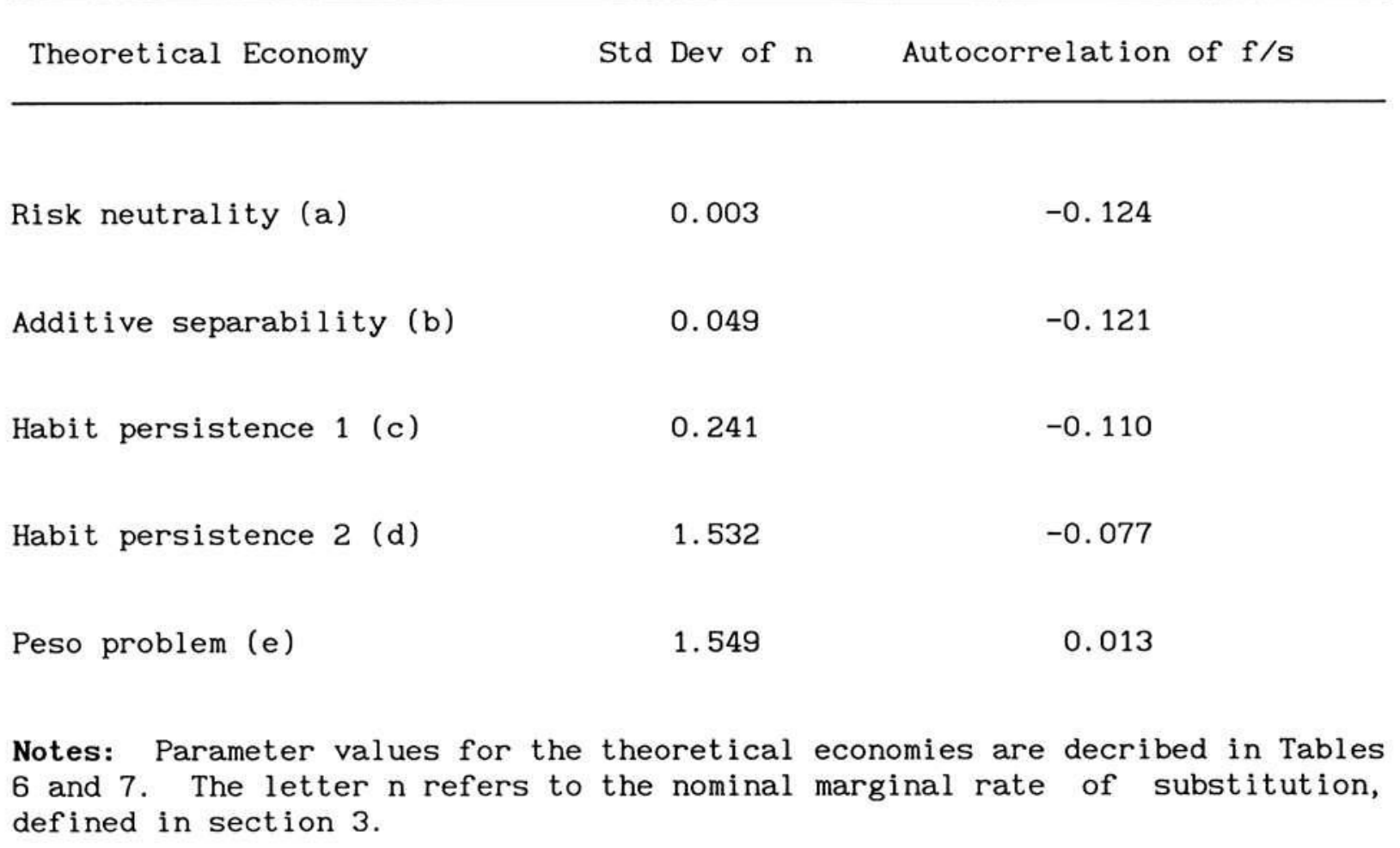

